\title{
Recovery Responses of Freshwater Phytoplankton Assemblage After the Disappearance of Metal Toxicity in Semi-Continuous Cultures
}

\author{
B. N. Tripathi ( $\square$ bhuminathtripathi@hotmail.com ) \\ Indira Gandhi National Tribal University https://orcid.org/0000-0001-9482-6935 \\ J. P. Gaur \\ Banaras Hindu University
}

\section{Research Article}

Keywords: Algal Community, Metal Toxicity, Natural assemblages, Phytoplankton, Recovery, Semi-continuous Culture

Posted Date: July 22nd, 2021

DOI: https://doi.org/10.21203/rs.3.rs-657719/v2

License: (a) (i) This work is licensed under a Creative Commons Attribution 4.0 International License. Read Full License 


\section{Abstract}

The present study demonstrates the recovery of phytoplankton assemblage from metal stress. Phytoplankton assemblage consisting of different freshwater algal species isolated from a tropical pond was exposed to sublethal concentrations of $\mathrm{Cu}$ and $\mathrm{Zn}$ for 25 days in semi-continuous culture (Toxicity phase). Subsequently, algal assemblage grown in the toxicity phase were transferred to the fresh culture medium without elevated levels of the test metals for 25 days in semi-continuous culture (Recovery phase). We monitored the total biovolume of each algal species during the toxicity and recovery phases. The members of Cyanophyta were most sensitive against metal toxicity, followed by the members of Bascillariophyta. However, the members of Chlorophyta showed relatively lesser sensitivity against test metals. Among chlorophytes, Scendesmus opolinensis and Cosmarium bioculatum were tolerant to both the test metals. Metal-stressed algal species showed recovery after transferring to the basal medium depending on the concentration of metals during the toxicity phase. The members of Cyanophyta were unable to recover from metal stress. However, members of Chlorophyta showed faster recovery than others from Zn stress, and the members of Bascillariophyta showed quicker recovery from $\mathrm{Cu}$ stress. The differential abilities of various algal species to recover from metal stress perhaps depend on their ability to counterbalance metal toxicity. Further, research is warranted to characterize the differential ability of various algal groups to recover from metal stress. The present findings would help understand the efficiency of different algal groups to restore their position within the freshwater algal community after the disappearance for metal stress.

\section{Introduction}

The metal contamination in water bodies is increasing rapidly due to the input of wastes from metal-related industries (Mishra et al. 2019; Hader et al. 2020). Microalgae have been proved suitable to evaluate the toxic responses of these metals in the aquatic environment (Rai et al. 1981; Pinto et al. 2003; Tripathi et al. 2003; Pandey 2020). A large number of single-species laboratory experiments have demonstrated the sensitivity of algae to heavy metals (Tripathi et al. 2004; Tripathi and Gaur 2004; Tripathi et al. 2006; Khatiwada et al. 2020). These tests can provide valuable information on concentrations of chemicals that might affect the survival, reproduction, physiology, and behaviour of individuals. Nevertheless, the experiments involving a single species cannot precisely extrapolate effects at higher levels of biological organization, i.e., population, community, and ecosystem processes, such as competition, predation and succession, and properties of an ecosystem, such as species diversity, result from the interplay of heterogeneous natural populations (Cairns 1983; Hamala and Kollig 1985; Magalhães et al. 2015).

Moreover, the test alga used in single-species tests may not be the dominant species in a natural environment. Furthermore, a single species of algae never exists alone in the aquatic environment, which contains several species coexisting in a balanced community. Algal species composition and interaction in the community are essential parameters for observing the algal responses to elevated levels of heavy metals and other environmental stresses. Thus, experimenting with algal assemblage as a whole might offer results more meaningful to natural water bodies than any single species approach.

It is for these reasons that ecologists must place a greater emphasis on multispecies and community levels studies. Such studies exhibit many ecosystem properties that would be untestable in a single species bioassay. 
For example, several studies have been made to evaluate the effects of heavy metals on algal populations and communities using laboratory microcosms (Pandey et al. 2015; Fawaz et al. 2018), controlled ecosystem enclosures (Sharma et al. 2020) and natural algal assemblages [Pandey et al. 2015, Pandey and Bergey 2018; Pandey 2020).

However, testing at the community level often lacks replication and control and is likely to be environmentally unacceptable due to the large quantities of toxic substances used (Moermond et al. 2015). However, isolating part of a natural community, using controlled ecosystem enclosures and other such systems, allows replication of treatment levels and, adds statistical control, and limits the amount of toxicant needed (Wahl et al. 2015). Earlier, the underwater static chambers (Hamala and Kollig 1985) and flow-through channels (Chen and Lin 1997) have been used for similar partitioning of lotic ecosystems, but they may be challenging to randomize spatially in small streams and may not adequately duplicate natural streamflow conditions.

In situ study of effects of pollutants, including elevated concentrations of heavy metals, on algae is cumbersome, requiring a lot of efforts. On the other hand, microcosms based on a semi-continuous culture system can be very well used to study the effects of metals on algal assemblages under controlled conditions of the laboratory and require the least input. Furthermore, the long-term assessment of the impact of the metal stress on algal populations is easily possible with semi-continuous culture, which does not change the levels of nutrients and pH (Tripathi et al. 2003; Tripathi et al. 2009). On the other hand, batch cultures suffer from the depletion of nutrients and fluctuation in the $\mathrm{pH}$ with time (Tripathi et al. 2003; Tripathi et al. 2009).

Further, it has been observed that industrial and domestic effluents very often cause discontinuous or episodic discharge of pollutants, such as metal ions, into receiving water bodies. Moreover, complexation by naturally occurring ligands may also sometimes significantly reduce the concentration of metals in water bodies.

Therefore, concentrations of heavy metals in a water body may at times become high due to episodic discharge or reduced availability of complexing ligands and subsequently get diluted with the passage of time and enable the metal-stressed algal population to recover their position in the aquatic ecosystem. But most of the studies involving natural algal assemblage have analyzed the structural and functional changes of algal communities during the period having elevated levels of toxic metals. The information on the recovery of the algal community after the disappearance of metal stress remains little explored. However, Pandey and Bergey (2018) have studied the recovery of algal populations after removing metal stress. But these researchers have demonstrated the recovery response of only a single group of algae (periphytic diatoms). As stated earlier, different groups of algal species coexist in nature and form a balanced algal community. Hence, studying the recovery response of a single group of algae does not provide accurate information about the recovery of whole algal community existing together in the ecosystem.

Further, studying recovery is essential because algal cells can resume their normal metabolic functions and growth after the disappearance of adverse environmental conditions (Tripathi et al. 2004; Tripathi and Gaur 2006). Algal species inhabiting such water bodies will not face much of a problem if they can tolerate high metal concentrations and can recover when the concentration returns to the background level. Further, recovery processes must be considered important factors having implications on algal community structure. To maintain or regain their position within the community, populations must sustain their growth rate or resuming growth after the disappearance of metal stress. Therefore, the present study was designed to understand the recovery 
responses of phytoplanktonic species living together in the form of a freshwater algal community after the disappearance of the elevated levels of metals (Cu and $\mathrm{Zn}$ ) using semi-continuous culture.

\section{Materials And Methods}

\section{Collection of Phytoplankton Sample}

The assemblage of phytoplankton employed for the study was collected from a eutrophic pond located at Kandwa, Varanasi. About two-liter water was collected from the pond in one liter polythene bottles. The water samples containing natural phytoplankton community were rushed to the laboratory and immediately processed for setting up the experiment. Zooplankton in water sample were killed by bubbling with nitrogen gas. Pond water was centrifuged and the phytoplankton assemblage was thus concentrated. For acclimatizing to laboratory conditions, the algal assemblage was transferred to the pre-sterilized algal assay medium (Chiaudani and Vighi 1978), and kept under fluorescent light giving $72 \mu \mathrm{mol} / \mathrm{m}^{2}$-s photosynthetically active radiation for 12 h daily at $27 \pm 2{ }^{\circ} \mathrm{C}$ for 10 days before the experiment was started. The $\mathrm{pH}$ of the culture medium was adjusted to 7.0 using $\mathrm{NaOH} / \mathrm{HCl}(0.1 \mathrm{~N})$. The cultures were hand shaken 3-4 times every day.

\section{Experimental Procedure}

After acclimatization to laboratory conditions for ten days, the algal assemblage was concentrated by centrifugation and the resulting dense assemblage was used as the inoculum. All the experiments presented in this chapter were conducted in semi-continuous cultures. A fixed volume $(1.0 \mathrm{ml})$ of inoculum of the concentrated algal assemblage was introduced into a $500 \mathrm{ml}$ flask containing $98 \mathrm{ml}$ of the culture medium. After 4 days of inoculation, the algal assemblage was dosed with one $\mathrm{ml}$ of stock solution of test metals prepared from $\mathrm{CuCl}_{2} \cdot 2 \mathrm{H}_{2} \mathrm{O}$ and $\mathrm{ZnCl}_{2}$, respectively, to obtain the desired concentrations of $\mathrm{Cu}(0.5,1.0$, and 2.5 $\mu \mathrm{M})$ and $\mathrm{Zn}(1,5,10 \mu \mathrm{M})$ in $100 \mathrm{ml}$ of culture suspension. These concentrations of the test metals were selected based on a preliminary screening of growth inhibition tests of representative phytoplanktonic species. The dilution of all the replicates $(n=3)$ of semi-continuous cultures started the day after metal enrichment. The dilution of culture was carried out in the morning hours by withdrawing carefully $25 \mathrm{ml}$ culture suspension from the control flasks as well as those treated with selected concentrations of $\mathrm{Cu}$ or $\mathrm{Zn}$. Exactly the same volume of fresh culture medium, not enriched with heavy metals in the case of the control and enriched with various concentrations of test metals in the case of treatments, was added to each flask so that the volume of the culture suspension did not change with time. Algal species were enumerated at a five-day interval up to the 25 th day (toxicity period). On the 25th, day, the algal suspension were transferred to the fresh culture medium not supplemented with higher concentrations of test metals to test the recovery of populations of different algal species. Regular dilution of culture suspension every day in the morning, and enumeration of algal species at a 5 day time interval continued up to the 25 th day of the transfer of the assemblage to the fresh medium (Recovery period).

\section{Enumeration and Identification of Algal species, and Calculation of Biovolume}

Algal species were counted with a Spencer's brightline hemocytometer. Biomass of each species was determined by transforming the cell count data to total biovolume. For the identification of different algal taxa, Desikachary (1959), Phillipose (1959), Prescott (1978) and other relevant literature were consulted. The 
biovolume of each algal species was calculated by using the software BIOVOLUME. For colonial species, the biovolume of a single cell was multiplied with cell density to derive total algal biovolume. For filamentous species, the cell number was multiplied by the volume of a single cell.

\section{Statistical Analyses}

The biovolume data of different algal species and groups collected for the entire duration of the experiment were statistically analyzed using one-way repeated measure analysis of variance (ANOVA). Time was used as the within subject factor (see table 2). The mean values of different parameters at different time points during exposure and recovery were compared by Tukey's HSD test. Tukey's HSD was calculated by hand. Whenever sphericity was significant, degrees of freedom and $\mathrm{F}$ values were corrected by Huynh-Feldt epsilon. Correlation coefficients were also calculated to establish relationships among different parameters.

\section{Results}

Figure 1 shows the response of different algal groups during exposure of an algal assemblage to $\mathrm{Cu}$, and also during recovery from $\mathrm{Cu}$ stress. The chlorophytes were the least sensitive to $\mathrm{Cu}$, whereas cyanophytes were the most sensitive and bacillariophytes occupied an intermediate position. The total biovolume of chlorophytes at 0.5 and $1 \mu \mathrm{M}$ Cu was almost similar to that of the control up to the day 15 , but it declined subsequently. However, the total biovolume was reduced right from the beginning of the experiment till the end of exposure to $2.5 \mu \mathrm{M} \mathrm{Cu}$ (day 25). The total biovolume of cyanophytes declined sharply after $\mathrm{Cu}(1.0$ and $2.5 \mu \mathrm{M})$ treatment, and these organisms disappeared by the end of the exposure period except for the assemblage exposed to 0.5 $\mu \mathrm{M} \mathrm{Cu}$. Nevertheless, cyanophytes were poorly represented at $0.5 \mu \mathrm{M} \mathrm{Cu}$. Reduction in total biovolume of bacillariophytes was noticed in the presence of $\mathrm{Cu}$ but the reduction was lesser than that for cyanophytes. When the assemblage was transferred to the basal medium, bacillariophytes recovered faster than the others. Chlorophytes showed a slow recovery after transferring Cu-treated assemblage to the metal unenriched medium. The members of Cyanophyta could survive only at $0.5 \mu \mathrm{M}$ Cu treatment, and showed a little recovery after withdrawing Cu stress.

Figure 2 shows the changes in the total biovolume of different algal groups exposed to different concentrations of $\mathrm{Zn}$, and also upon transfer to the basal medium. Green algae appeared most tolerant to Zn followed by diatoms and blue greens. In comparison to the control, the total biovolume of chlorophytes increased during exposure to $1 \mu \mathrm{M} Z \mathrm{n}$ as well as during recovery. However, further increase in concentration of $\mathrm{Zn}$ led to inhibition. The total biovolume of cyanophytes sharply reduced after 5 and $10 \mu \mathrm{M} Z n$ treatments, but did not differ much from the control at $1 \mu \mathrm{M} Z \mathrm{n}$. The total biovolume of diatoms declined in presence of $\mathrm{Zn}$ in a concentration-dependent manner. The total biovolume of diatoms recovered slowly depending on concentration of $\mathrm{Zn}$ used for the treatment.

Table 1 contains the list of algal species encountered in the assemblage. Chlorophyta was most well represented followed in decreasing order by Cyanophyta and Bacillariophyta. Euglenophyta was represented by only Phacus sp. The table also shows that three species disappeared during the course of the experiment even in the control. Metal treatment caused disappearance of a number of species in the assemblage. Higher the concentration of a metal, greater was the disappearance of species. Maximum disappearance of species was encountered at $2.5 \mu \mathrm{M}$ of $\mathrm{Cu}$ and $10 \mu \mathrm{M}$ of $\mathrm{Zn}$. The members of Cyanophyta disappeared at higher 
concentrations of both the metals, whereas none of the diatom species could disappear even at the highest tested concentrations of test metals.

Figure 3 shows the response of four species of Scenedesmus (Chlorophyta) to elevated levels of Cu. The figure makes it amply clear that $S$. opolinensis was tolerant to $\mathrm{Cu}$ as the size of its population always remained higher in Cu-treated cultures than in the control. The higher population of this species was evident during the exposure as well as the recovery period. $S$. quadricauda and $S$. dimorphus were only slightly inhibited by Cu in a concentration-dependent manner. However, S. bijugatus displayed a marked sensitivity to $\mathrm{Cu}$. Its population declined during exposure to $\mathrm{Cu}$ in a concentration-dependent manner. Another noteworthy feature of this species has been its ability to quickly recover from metal stress after its transfer to the basal medium not enriched with $\mathrm{Cu}$.

Figure 4 shows the total biovolume of some other green algal species in the presence of $\mathrm{Cu}$ and after transfer to the basal medium. Ankistrodesmus falcatus, Zygnema sp., and Chlorella vulgaris were very much sensitive to $\mathrm{Cu}$, with their total biovolume declining in a concentration-dependent manner. At $2.5 \mu \mathrm{M} \mathrm{Cu}, C$. vulgaris and Zygnema sp. disappeared; $1.0 \mu \mathrm{M} \mathrm{Cu}$ also caused the disappearance of Zygnema sp. After transfer to the fresh basal medium, $A$. falcatus, $C$. vulgaris, and Zygnema sp. started to recover at different rates depending on the concentration of $\mathrm{Cu}$ given during the exposure period. On the other hand, Cosmarium bioculatum was highly tolerant to $\mathrm{Cu}$, showing increase in its total biovolume with increasing $\mathrm{Cu}$ concentration. After withdrawing $\mathrm{Cu}$ stress, the total biovolume of $C$. bioculatum remained unchanged or begun to decline very slowly but it still remained considerably higher than the control.

The members of Cyanophyta were very much sensitive to $\mathrm{Cu}$, and they disappeared during the course of $\mathrm{Cu}$ exposure. Only Aphanocapsa banarensis could survive in $0.5 \mu \mathrm{M} \mathrm{Cu}$, and it started to recover after the withdrawing of Cu stress (Fig. 5).

Figure 6 shows the total biovolume of some major bacillariophycean taxa during exposure to $\mathrm{Cu}$ and also during recovery. All the species showed inhibitory effect of $\mathrm{Cu}$ on their total biovolume in a concentration-dependent fashion. All diatom species were also able to recover depending on the concentration of Cu that was used for their exposure. Higher the concentration of $\mathrm{Cu}$ during exposure, slower was the rate of recovery of the total biovolume of all the diatom species.

Figure 7 shows total biovolume of major green algal species during exposure to $\mathrm{Zn}$ and also during recovery. The total biovolume of $S$. quadricauda was always greater than the control at $1 \mu \mathrm{M} Z \mathrm{n}$. However, it remained almost similar to that of the control at $5 \mu \mathrm{M} Z \mathrm{n}$. S. bijugatus was slightly more sensitive to Cu than $S$. quadricauda; its population was greatly diminished at $10 \mu \mathrm{M} Z \mathrm{n}$. S. dimorphus showed an interesting response after exposure to 1 and $10 \mu \mathrm{M} \mathrm{Zn;} \mathrm{its} \mathrm{total} \mathrm{biovolume} \mathrm{remained} \mathrm{considerably} \mathrm{higher} \mathrm{than} \mathrm{that} \mathrm{of} \mathrm{the} \mathrm{control.} \mathrm{But,}$ its total biovolume remained almost similar to that of the control at $5 \mu \mathrm{M} \mathrm{Zn}$. S. opolinensis was tolerant to $\mathrm{Zn}$ also as a regular increase in total biovolume of $S$. opolinensis occurred with the passage of time. The recovery of the total biovolume of $S$. quadricauda and $S$. bijugatus from 10 and $5 \mu \mathrm{M} Z \mathrm{n}$, respectively, occurred rather slowly, however, it was quicker in other cases.

A $10 \mu \mathrm{M} Z \mathrm{n}$ caused the disappearance of Chlorella vulgaris and Zygnema sp. (Fig. 8). Zygnema sp. disappeared at $5 \mu \mathrm{M} \mathrm{Zn}$ also. Ankistrodesmus falcatus was sensitive to $\mathrm{Zn}$ and its total biovolume decreased in a concentration-dependent manner. On the other hand, Cosmarium bioculatum showed a remarkable tolerance to 
all the tested concentrations of Zn. The figure also shows recovery of $A$. falcatus, $C$. vulgaris and Zygnema that depended on the concentration of $\mathrm{Zn}$ to which they were exposed (Fig. 8).

Figure 9 shows the total biovolume of major cyanophytes during exposure to Zn and also during recovery. Merismopedia sp. was unable to sustain at any tested concentration of $\mathrm{Zn}$, and Microcystis aeruginosa and Chroococcus limneticus disappeared at 5 and $10 \mu \mathrm{M} Z \mathrm{Zn}$. Aphanocapsa banarensis remained alive at 1 and 5 $\mu \mathrm{M} Z \mathrm{n}$. The biovolume of each species was considerably reduced by metal treatment. After the transfer of the assemblage to the fresh medium all the species did not show recovery.

Figure 10 shows the response of bacillariphycean members during exposure to $\mathrm{Zn}$ and also during recovery. The total biovolume of Navicula radiosa, Synedra sp., Nitzschia palea and Cyclotella sp. declined depending on the concentration of Zn. N. palea disappeared completely at $10 \mu \mathrm{M} Z \mathrm{n}$. The biovolume of Cyclotella sp. exposed to $1 \mu \mathrm{M} Z \mathrm{n}$ was not different from that of the control. Biovolume of all the species of Bacillariophyta, which had earlier declined under $\mathrm{Zn}$ stress, started to recover when the algal assemblage was transferred to the fresh basal medium.

\section{Discussion}

During the establishment of the phytoplankton assemblage in the laboratory, three species namely Pediastrum sp., Lyngbya sp. and Phacus sp. were eliminated from the control culture with time. These species perhaps could not find laboratory conditions congenial for their growth and multiplication. Despite this limitation, the assemblage was deleteriously impacted by the test metals depending upon their concentrations in the external environment.

Algal groups in the assemblage displayed large-scale variations in their sensitivity to test metals. The members of Cyanophyta, now preferably called Cyanobacteria, were the most sensitive followed by the members of Bacillariophyta and Chlorophyta. The present observations slightly differ from Singh and Rai (1990) who noted the following order of Zn sensitivity to algal groups: Cyanophyta > Chlorophyta > Bacillariophyta. Marked sensitivity of the members of Cyanophyta to test metals was evident from the data on their total biovolume. Moreover, almost all of them disappeared from the medium containing the highest tested concentrations of test metals. Greater metal tolerance of chlorophytes compared to cyanophytes in the present case agrees well with some previous studies. Earlier studies (Foster 1982) also observed green algae, especially the members of Ulotrichales, remarkably tolerant to heavy metals. Like the present observations, Genter et al. (1987) noticed greater tolerance to $\mathrm{Zn}$ in green algae than in diatoms. They observed a marked change in composition of an algal community from diatoms to filamentous green algae and finally to unicellular green algae with increase in concentration of $\mathrm{Zn}$ in an experimental stream. Takamura et al. (1989) also observed greater tolerance of green algae to $\mathrm{Cu}, \mathrm{Cd}$ and $\mathrm{Zn}$, whereas cyanophytes were most sensitive to test metals. According to them, isolates of cyanophytes from polluted waters may also show sensitivity to heavy metals. On the other hand, many researchers showed greater metal tolerance in algae isolated from habitats polluted with heavy metals. Variations in sensitivities of algal groups to metal ions are difficult to explain in the light of available evidence. However, marked sensitivity of cyanophytes to test metals may be related to their cell structure. Owing to prokaryotic cellular organization, characterized inter alia by lack of membrane-bound organelles, the test metals could enter their cell and damage the sensitive sites with considerable ease. 
The present study showed that the populations of Scenedesmus opolinensis and Cosmarium bioculatum considerably increased following metal enrichment. The increase was of a relatively higher magnitude compared to the control. Obviously, these two green algal species are tolerant to both the test metals. Greater metal tolerance of these two species together with elimination of competing species, that were probably metal sensitive, had possibly led to a very large increase in their populations. Concurrent tolerance of S. opolinensis and $C$. bioculatum to $\mathrm{Cu}$ and $\mathrm{Zn}$ may have resulted through multiple tolerance or co-tolerance (Venâncio et al. 2016), but which one of the two was operating in these two organisms is difficult to pin point. Laboratory experiments in future can only throw light on the mode of concurrent tolerance to test metals in the present study. Unlike $S$. opolinensis and $C$. bioculatum which showed tolerance to both the test metals, Scenedesmus dimorphus displayed tolerance to only $\mathrm{Zn}$. It appears that the tolerance to $\mathrm{Zn}$ is highly metal-specific in $S$. dimorphus.

Four species of Scenedesmus present in the phytoplankton assemblage displayed marked variations in their sensitivity upon exposure to elevated levels of test metals, and also during recovery. $S$. opolinensis seemed to be highly tolerant and $S$ quadricuda and $S$. dimorphus were moderately tolerant to metals. On the other hand, $S$. bijugatus showed a marked sensitivity to metals but was able to quickly recover from metal stress. Such a variable response of different species belonging to the same genus gets support from the study of Kessler (1985). He found one strain of Chlorella saccharophila about 100 times more sensitive than 14 other strains belonging to five species of Chlorella.

Metal-stressed communities were able to recover after they were transferred to the basal medium. However, the extent of recovery depended on the concentration of metal to which a community was exposed. Greater the concentration of metal used for exposure, lower was the extent up to which the community was able to recover. This response seems to be related with intracellular content of test metals in algal cells, which got gradually diluted with cell division during the course of recovery. In this context, it deserves mention that intracellular metal is primarily responsible for toxicity of a metal (Tripathi and Gaur 2004). The individuals in the assemblage exposed to higher concentrations of test metals accumulated larger intracellular concentrations of test metals, which could not be sufficiently diluted with cell division during the limited period ( 25 days) of recovery, and therefore only partial recovery could occur.

Amongst the algal groups, cyanophytes were generally not able to recover from metal stress, and this is again an evidence of their marked sensitivity to heavy metals. Of the other two groups, recovery was the best in chlorophytes from Zn stress and in diatoms from Cu stress. The present study does not permit explanation of this variability in response of algal groups to recovery. However, Mallin et al. (1994) found chlorophytes better able to recover from $\mathrm{Cu}$ and $\mathrm{Zn}$ stresses compared to bacillariophytes.

\section{Conclusions}

The present study deals with the changes in the structure of a phytoplankton assemblage studied during exposure (for 25 days) to $\mathrm{Cu}$ and $\mathrm{Zn}$ and during recovery (for 25 days) upon transfer to the basal medium not enriched with test metals. Algal groups displayed marked variations in their sensitivity to the test metals. Individuals belonging to Cyanophyta were most sensitive, followed by those of Bacillariophyta and Chlorophyta. However, the marked sensitivity of cyanophytes to test metals may be related to their cell structure. Owing to the prokaryotic cellular organization, characterized inter alia by lack of membrane-bound organelles, the test metals 
could enter their cell and damage the sensitive sites with considerable ease. Among chlorophytes, Scendesmus opolinensis and Cosmarium bioculatum were tolerant to both the test metals. Concurrent tolerance of $S$. opolinensis and $C$. bioculatum to $\mathrm{Cu}$ and $\mathrm{Zn}$ may have achieved through multiple tolerance or co-tolerance, but which one of the two was operating in these two organisms is difficult to conclude. Metal-stressed communities were able to recover after they were transferred to the basal medium. However, the extent of recovery depended on the concentration of metal to which a community was exposed. The algal assemblage was able to recover quickly after withdrawing metal stress. The recovery of the algal assemblage was higher when it was treated with lower concentrations of test metals. Among the algal groups, cyanophytes were generally unable to recover from metal stress, which is again evidence of their marked sensitivity to heavy metals. Of the other two groups, recovery was the best in chlorophytes from $\mathrm{Zn}$ stress and in diatoms from Cu stress.

\section{Declarations}

\section{Acknowledgement}

BNT is grateful to Council of Scientific and Industrial Research, New Delhi for financial support.

Data Availability: The manuscript has not associated data.

Animal Research (Ethics): The work does not involve any animals or animal cell.

Consent to Participate (Ethics): Not applicable.

Consent to Publish (Ethics): We provide our consent for the publication.

Plant Reproducibility: Not applicable.

Clinical Trials Registration: Not applicable.

\section{Author's Contribution}

BNT has designed and performed the experiments and wrote the manuscript, JPG has supervised the work, analyzed the statistical data and wrote and corrected the manuscript.

Conflict of Interest: We declare no conflict of interest.

Funding: Council of Scientific and Industrial Research, New Delhi, India.

\section{References}

1. Cairns J Jr (1983) Are single species toxicity test alone adequate for estimating environmental hazards? Hydrobiologia 100: 47-57

2. Chen CY, Lin KC (1997) Optimization and performance evaluation of the continuous algal toxicity test. Environ Toxicol Chem 16: 1337-1344

3. Chiaudani G, Vighi M (1978) The use of Selenastrum capricornutum batch cultures in toxicity studies. Mitt Int Verein Limnol 21: 316-329 
4. de Paiva Magalhães D, da Costa Marques MR, Baptista DF, Buss DF (2015) Metal bioavailability and toxicity in freshwaters. Environ Chem Lett 13: 69-87

5. Desikachary TV (1959) Cyanophyta. Indian Council of Agriculture Research, New Delhi.

6. Fawaz EG, Salam DA, Kamareddine L (2018) Evaluation of copper toxicity using site specific algae and water chemistry: Field validation of laboratory bioassays. Ecotoxicol Environ Safety 155: 59-65

7. Foster PL (1982) Metal resistance of Chlorophyta from rivers polluted by heavy metals. Freshwater Biol 12: 41-61

8. Genter RB, Cherry DS, Smith EP, Cairns J Jr (1987) Algal periphyton and community changes from zinc stress in stream mesocosms. Hydrobiologia 153: 261-275

9. Häder DP, Banaszak AT, Villafañe VE, Narvarte, MA, González RA, Helbling EW (2020) Anthropogenic pollution of aquatic ecosystems: Emerging problems with global implications. Sci Total Environ 713: 136586

10. Hamala JA, Kollig HP (1985) The effect on periphyton communities in controlled laboratory ecosystems. Chemosphere 14: 1391-1408

11. Kessler E (1985) An extremely cadmium sensitive strain of Chlorella. Experientia 41: 1621

12. Khatiwada B, Hasan MT, Sun A, Kamath KS, Mirzaei M, Sunna A, Nevalainen H (2020) Proteomic response of Euglena gracilis to heavy metal exposure-Identification of key proteins involved in heavy metal tolerance and accumulation. Algal Research 45: 101764

13. Mallin MA, Stone KL, Pamperl MA (1994) Phytoplankton community assessment of seven U.S. cooling reservoirs. Water Res 28: 665-673

14. Mishra S, Bharagawa RN, More N, Yadav A, Zainith S, Mani S, Chowdhary P (2019) Heavy Metal Contamination: An Alarming Threat to Environment and Human Health. In: Sobti, R., Arora, N., Kothari R. (eds.) Environmental Biotechnology: For Sustainable Future. Springer, Singapore, pp. 103-125

15. Moermond CTA, Kase R, Korkaric M, Ågerstrand M (2016) CRED: Criteria for reporting and evaluating ecotoxicity data. Environ Toxicol Chem 35: 1297-1309

16. Pandey LK (2020) In situ assessment of metal toxicity in riverine periphytic algae as a tool for biomonitoring of fluvial ecosystems, Environ Technol Innov 18:100675

17. Pandey LK, Bergey EA (2018) Metal toxicity and recovery response of riverine periphytic algae. Sci Total Environ 642: 1020-1031

18. Pandey LK, Han T, Gaur JP (2015) Response of a phytoplanktonic assemblage to copper and zinc enrichment in microcosm. Ecotoxicology 24: 573-582

19. Phillipose MT (1959) Chlorococcales. Indian Council of Agriculture Research, New Delhi.

20. Pinto E, Sigaud-kutner TCS, Leitao MAS, Okamoto OK, Morse D, Colepicolo P (2003) Heavy metal-induced oxidative stress in algae. J Phycol 39: 1008-1018

21. Prescott GW (1978) How to know the freshwater algae? third ed. Wm C Brown Company Publishers, lowa

22. Rai LC, Gaur JP, Kumar HD (1981). Phycology and heavy-metal pollution. Biol Rev 56: 99-151

23. Sharma KV, Sarvalingam BK, Marigoudar SR (2021) A review of mesocosm experiments on heavy metals in marine environment and related issues of emerging concerns. Environ Sci Pollut Res 28:1304-1316 
24. Singh AK, Rai LC (1990) Use of in situ structural and functional variables of phytoplankton of the river Ganga for assessment of heavy-metal toxicity. Biomed Environ Sci 3: 397-405

25. Takamura N, Kasai F, Watanabe MM (1989) Effects of Cu, Cd and Zn on photosynthesis of freshwater benthic algae. J Appl Phycol 1: 39-52

26. Tripathi BN, Gaur JP (2004) Relationship between copper- and zinc-induced oxidative stress and proline accumulation in Scenedesmus sp. Planta 219: 397-404

27. Tripathi BN, Gaur JP (2006) Physiological behavior of Scenedesmus sp. during exposure to elevated levels of $\mathrm{Cu}$ and $\mathrm{Zn}$ and after withdrawal of metal stress. Protoplasma 229: 1-9

28. Tripathi BN, Kasana R, Singh V, Bhatt I, Singh A, Sharma V, Gaur JP (2009) Carotenoids and pH of the culture medium play important role in displaying metal stress in batch and semi-continuous cultures of Anabaena doliolum. Annal Limnol 45: 1-7

29. Tripathi BN, Mehta SK, Gaur JP (2003) Differential sensitivity of Anabaena doliolum to Cu and Zn in batch and semi-continuous culture. Ecotoxicol Environ Safety 56: 311-318

30. Tripathi BN, Mehta SK, Gaur JP (2004) Recovery of uptake and assimilation of nitrate in Scenedesmus sp. previously exposed to elevated levels of $\mathrm{Cu}^{2+}$ and $\mathrm{Zn}^{2+}$. J Plant Physiol 161: 543-549

31. Tripathi BN, Singh A, Gaur JP (2000) Impact of heavy metal pollution on algal assemblages. Environ Sci 9: 1-7

32. Venâncio C, Ribeiro R, Soares A, Lopes I (2016) Multiple stressor differential tolerances: Possible Implications at the population level. PLOS ONE 11: e0151847

33. Wahl M, Saderne V, Sawall Y (2015) How good are we at assessing the impact of ocean acidification in coastal systems? Limitations, omissions and strengths of commonly used experimental approaches with special emphasis on the neglected role of fluctuations. Mar Fresh Res 67: 25-36

\section{Tables}

Table 1.: Algal species in the control and metal-treated phytoplankton assemblage. 


\begin{tabular}{|lccccccccc}
\hline & Control & $\mathrm{Cu}$ & $\mathrm{Cu}$ & $\mathrm{Cu}$ & $\mathrm{Zn}$ & $\mathrm{Zn}$ & $\mathrm{Zn}$ \\
& & & & & & & 10.0 \\
& & 0.5 & 1.0 & 2.5 & 1.0 & 5.0 & $\mu \mathrm{M}$ \\
Species & & $\mu \mathrm{M}$ & $\mu \mathrm{M}$ & $\mu \mathrm{M}$ & $\mu \mathrm{M}$ & $\mu \mathrm{M}$ & \\
& & & & & & &
\end{tabular}

\section{Chlorophyta}

\section{Ankistrodesmus falcatus}

Chlorella vulgaris

Closterium sp.

D

D

D

Cosmarium bioculatum

Pediastrum sp.

D

D D

D

D D

Scenedesmus

D

bijugatus

S. dimorphus

S. opolinensis

\section{S. quadricauda}

Zygnema sp.

D

D

D

\section{Cyanophyta}

\section{Aphanocapsa banarensis}

D D

D

Chroococcus limneticus

D D D

D

D

Lyngbya sp.

D

D D

Merismopedia minor

D D

D

D

D

D

Microcystis aeruginosa

D

D

D

D

D

Bacillariophyta

\section{Cyclotella sp}


Navicula radiosa

Nitzschia palea

Synedra sp.

\section{Euglenophyta}

Phacus sp

Number of Species disappeared
D

3
D

9

9

$\begin{array}{llll}10 & 2 & 6 & 11\end{array}$

'D' denotes disappearance of species during the course of the experiment; species not marked with D were, however, present.

Table 2. Summary of one-way repeated measure analysis of variance (ANOVA) on biovolume of algal groups and major algal species in phytoplankton assemblage at different time intervals during exposure and recovery in semi-continuous culture. Values are $\mathrm{F}$ ratio. 


\begin{tabular}{|c|c|c|c|c|c|c|c|c|}
\hline $\begin{array}{l}\text { Algal } \\
\text { group/species }\end{array}$ & $\mathrm{df}$ & Control & $\begin{array}{l}\text { Cu } 0.5 \\
\mu \mathrm{M}\end{array}$ & Cu $1 \mu \mathrm{M}$ & $\begin{array}{l}\text { Cu } 2.5 \\
\mu \mathrm{M}\end{array}$ & $\mathrm{Zn} 1 \mu \mathrm{M}$ & $\begin{array}{l}\text { Zn } 5 \\
\mu \mathrm{M}\end{array}$ & $\begin{array}{l}\mathrm{Zn} 10 \\
\mu \mathrm{M}\end{array}$ \\
\hline Total & 9 & $1260.0^{\star \star \star}$ & $516.3^{\star \star \star}$ & $427.2^{\star \star \star}$ & $382.6^{\star \star \star}$ & $476.4^{\star \star \star}$ & $394.5^{\star \star \star}$ & $306.3^{\star \star \star}$ \\
\hline Chlorophyta & 9 & $398.4^{\star \star \star}$ & $211.5^{\star \star \star}$ & $296.3^{\star \star \star}$ & $203.5^{\star \star \star}$ & $253.6^{\star \star \star}$ & $311.7^{\star \star \star}$ & $209.5^{\star \star \star}$ \\
\hline Cyanophyta & 9 & $261.0^{\star \star \star}$ & $96.0^{\star \star \star}$ & $105.6^{\star \star \star}$ & $99.2^{\star \star \star}$ & $117.3^{\star \star \star}$ & $109.5^{\star \star \star}$ & $87.6^{\star \star \star}$ \\
\hline Bacillariophyta & 9 & $108.6^{\star \star \star}$ & $16.2^{\star \star \star}$ & $83.6^{\star \star \star}$ & $78.4^{\star \star \star}$ & $24.5^{\star \star \star}$ & $107.9^{\star \star \star}$ & $63.3^{\star \star \star}$ \\
\hline \multicolumn{9}{|l|}{ Chlorophyta } \\
\hline SQ & 9 & $157.9^{\star \star \star}$ & $133.8^{\star \star \star}$ & $83.1^{\star \star \star}$ & $48.3^{\star \star \star}$ & $142.6^{\star \star \star}$ & $127.6^{\star \star \star}$ & $86.5^{\star \star \star}$ \\
\hline SB & 9 & $59.6^{\star \star \star}$ & $37.4^{\star \star \star}$ & $50.9^{\star \star \star}$ & $82.1^{\star \star \star}$ & $41.4^{\star \star \star}$ & $49.3^{\star \star \star}$ & $67.5^{\star \star \star}$ \\
\hline SD & 9 & $1292.6^{\star \star \star}$ & $519.7^{\star \star \star}$ & $669.7^{\star \star \star}$ & $384.7^{\star \star \star}$ & $417.2^{\star \star \star}$ & $442.5^{\star \star \star}$ & $392.3^{\star \star \star}$ \\
\hline so & 9 & $4.4^{\star \star \star}$ & $14.1^{\star \star \star}$ & $68.1^{\star \star \star}$ & $60.0^{\star \star \star}$ & $13.6^{\star \star \star}$ & $56.1^{\star \star \star}$ & $40.3^{\star \star \star}$ \\
\hline CV & 9 & $8.8^{* \star \star}$ & $58.3^{\star \star \star}$ & $9.3^{\star \star \star}$ & $31.8^{\star \star \star}$ & $55.5^{\star \star \star}$ & $11.6^{\star \star \star}$ & $52.6^{\star \star \star}$ \\
\hline CB & 9 & $247.4^{\star \star \star}$ & $1774.6^{\star \star \star}$ & $289.9^{\star \star \star}$ & $562.9^{\star \star \star}$ & $1554.0^{\star \star \star}$ & $302.3^{\star \star \star}$ & $497.4^{\star \star \star}$ \\
\hline $\mathrm{CL}$ & 9 & $9.9^{\star \star \star}$ & $52.6^{* \star \star}$ & $72.3^{\star \star \star}$ & $56.3^{\star \star \star}$ & $47.3^{\star \star \star}$ & $75.0^{\star \star \star}$ & $56.7^{\star \star \star}$ \\
\hline $\mathrm{AF}$ & 9 & $5.7^{\star \star \star}$ & $17.8^{\star \star \star}$ & $15.9^{\star \star \star}$ & $20.0^{\star \star \star}$ & $14.6^{\star \star \star}$ & $16.7^{\star \star \star}$ & $22.5^{\star \star \star}$ \\
\hline ZG & 9 & $131.1^{\star \star \star}$ & $348.5^{\star \star \star}$ & $1166.6^{\star \star \star}$ & $4743.5^{\star \star \star}$ & $34.2^{\star \star \star}$ & $1084.2^{\star \star \star}$ & $4525.1^{\star \star \star}$ \\
\hline \multicolumn{9}{|l|}{ Cyanophyta } \\
\hline$A B$ & 9 & $362.4^{\star \star \star}$ & $103.5^{\star \star \star}$ & $565.0^{\star \star \star}$ & $397.6^{\star \star \star}$ & 1.5 & $482.6^{\star \star \star}$ & $402.5^{\star \star \star}$ \\
\hline MI & 9 & $9.4^{\star \star \star}$ & $63.2^{\star \star \star}$ & $70.1^{\star \star \star}$ & $63.0^{\star \star \star}$ & $57.9^{\star \star \star}$ & $62.3^{\star \star \star}$ & $70.6^{\star \star \star}$ \\
\hline $\mathrm{CH}$ & 9 & 1.6 & $66.5^{\star \star \star}$ & $45.7^{\star \star \star}$ & $53.5^{\star \star \star}$ & $74.3^{\star \star \star}$ & $54.4^{\star \star \star}$ & $63.9^{\star \star \star}$ \\
\hline ME & 9 & 1.4 & $1126.0^{\star \star \star}$ & $999.1^{\star \star \star}$ & $1068.5^{\star \star \star}$ & $1098.4^{\star \star \star}$ & $1012.5^{\star \star \star}$ & $1025.3^{\star \star \star}$ \\
\hline \multicolumn{9}{|l|}{ Bacillariophyta } \\
\hline NA & 9 & $16.1^{\star \star \star}$ & $10.4^{\star \star \star}$ & $112.5^{\star \star \star}$ & $103.5^{\star \star \star}$ & $9.8^{\star \star \star}$ & $120.1^{\star \star \star}$ & $105.7^{\star \star \star}$ \\
\hline $\mathrm{NI}$ & 9 & $39.7^{\star \star \star}$ & $104.4^{\star \star \star}$ & $749.9^{\star \star \star}$ & $2390.6^{\star \star \star}$ & $115.6^{\star \star \star}$ & $694.3^{\star \star \star}$ & $2160.5^{\star \star \star}$ \\
\hline SY & 9 & $178.2^{\star \star \star}$ & $91.6^{\star \star \star}$ & $188.9^{\star \star \star}$ & $502.1^{\star \star \star}$ & $94.3^{\star \star \star}$ & $201.5^{\star \star \star}$ & $472.3^{\star \star \star}$ \\
\hline CY & 9 & $38.9^{\star \star \star}$ & $38.9^{\star \star \star}$ & $74.7^{\star \star \star}$ & $100.4^{\star \star \star}$ & $137.8^{\star \star \star}$ & $103.4^{\star \star \star}$ & $122.5^{\star \star \star}$ \\
\hline Error (Time) & 18 & & & & & & & \\
\hline
\end{tabular}


$\star \star \star P<0.001, * \star P<0.01, * P<0.05$

$\mathrm{AB}=$ Aphanocapsa banarensis $\mathrm{AF}=$ Ankistrodesmus falcatus, $\mathrm{CB}=$ Cosmarium bioculatum, $\mathrm{CH}=$ Chroococcus limneticus, $\mathrm{CL}=$ Closterium sp., $\mathrm{CV}=$ Chlorella vulgaris, $\mathrm{CY}=$ Cyclotella $\mathrm{sp} ., \mathrm{ME}=$ Merismopedia minor, $\mathrm{MI}=$ Microcystis aeruginosa, $\mathrm{NA}=$ Navicula radiosa, $\mathrm{NI}=$ Nitzschia palea, $\mathrm{SB}=$ Scenedesmus bijugatus, $\mathrm{SD}=$ Scenedesmus dimorphus, SO = Scenedesmus opolinensis, SQ = Scenedesmus qudricauda, SY = Synedra sp., ZG = Zygnema sp.

\section{Figures}

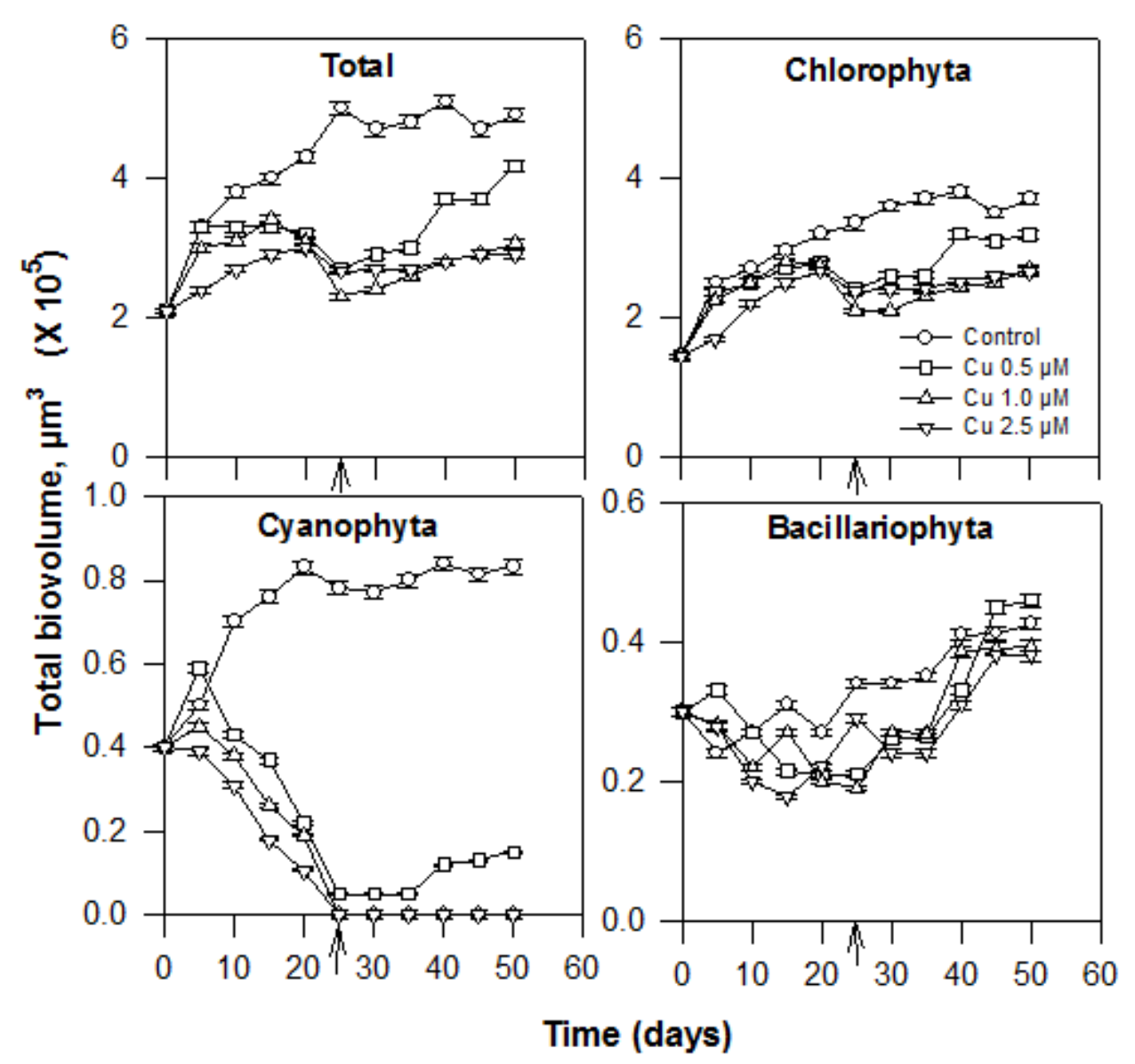

Figure 1

Total biovolume of individuals belonging to major algal groups during exposure of an algal assemblage to $\mathrm{Cu}$, and also during recovery. Arrow indicates the time of transfer to the metal un-enriched medium. Changes in the biovolume of different algal groups were statistically significant $(P<0.001$; see table 2$)$ with the passage of time. 


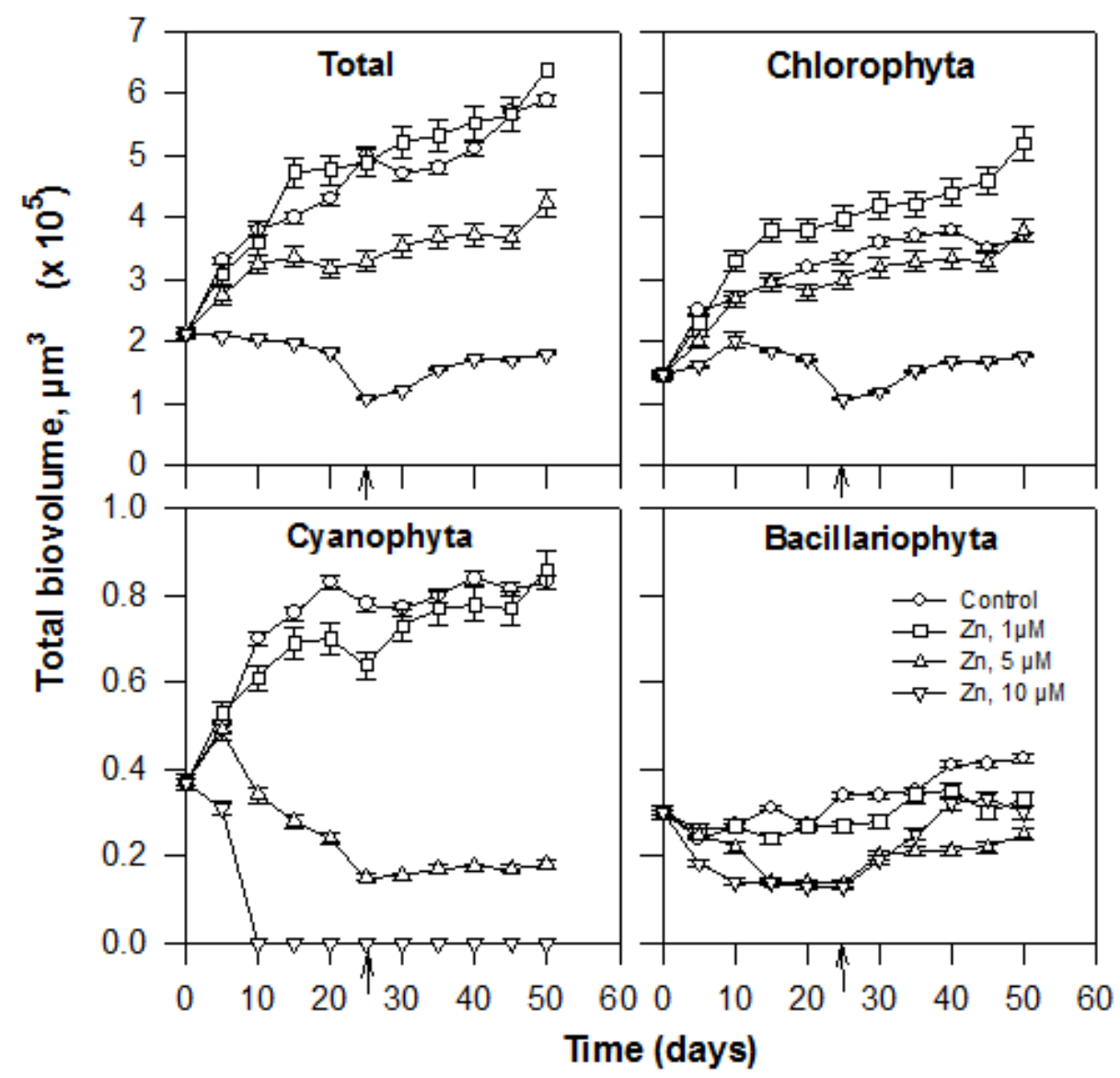

Figure 2

Total biovolume of individuals belonging to major algal groups during exposure of an algal assemblage to $\mathrm{Zn}$, and also during recovery. Arrows indicate the time the assemblage was transferred to metal un-enriched medium. Changes in the biovolume of different algal groups were statistically significant $(P<0.001$; see table 2$)$ with the passage of time. 

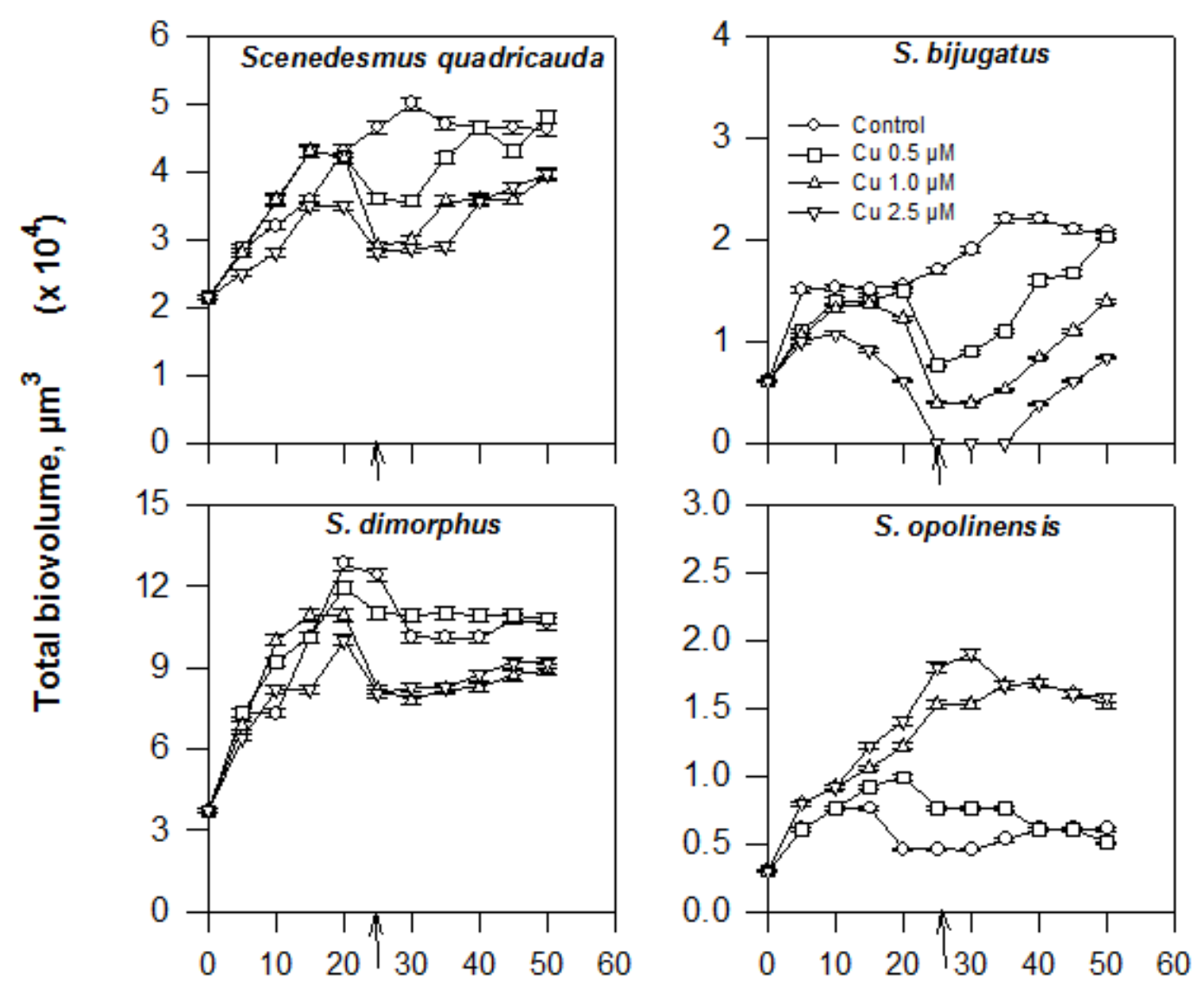

Figure 3

Total biovolume of four species of Scenedesmus (Chlorophyta) during exposure of the assemblage to $\mathrm{Cu}$, and also during recovery. Arrow indicates the time of transfer to the basal medium. Changes in the biovolume of four species of Scenedesmus were statistically significant $(P<0.001$; see table 2$)$ with the passage of time. 


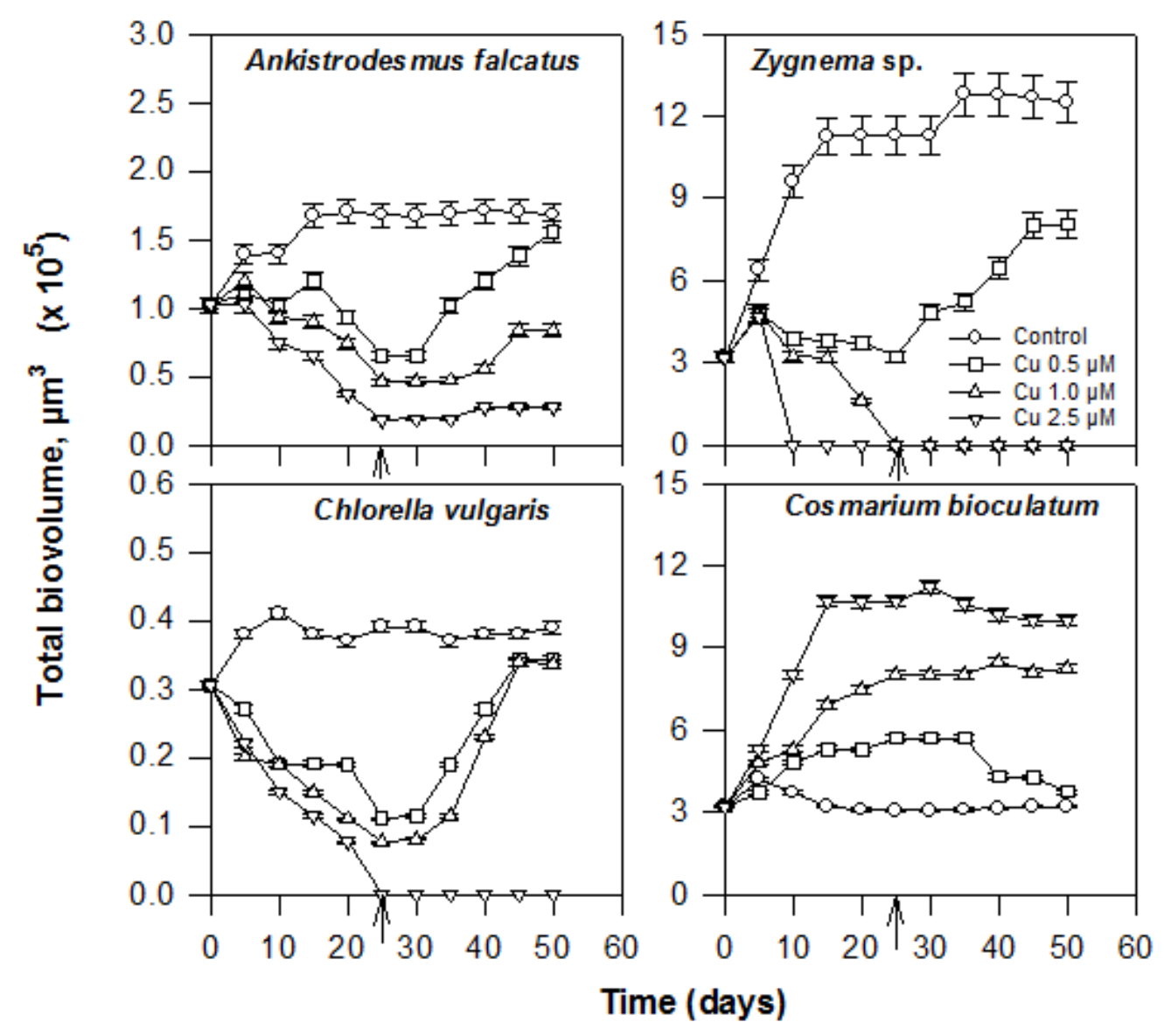

Figure 4

Total biovolume of some major green algal species during exposure of an algal assemblage to $\mathrm{Cu}$, and also during recovery. Arrow indicates the time of transfer to the basal medium. Changes in the biovolume of different green algal species were statistically significant $(P<0.001$, see table 2$)$ with the passage of time. 


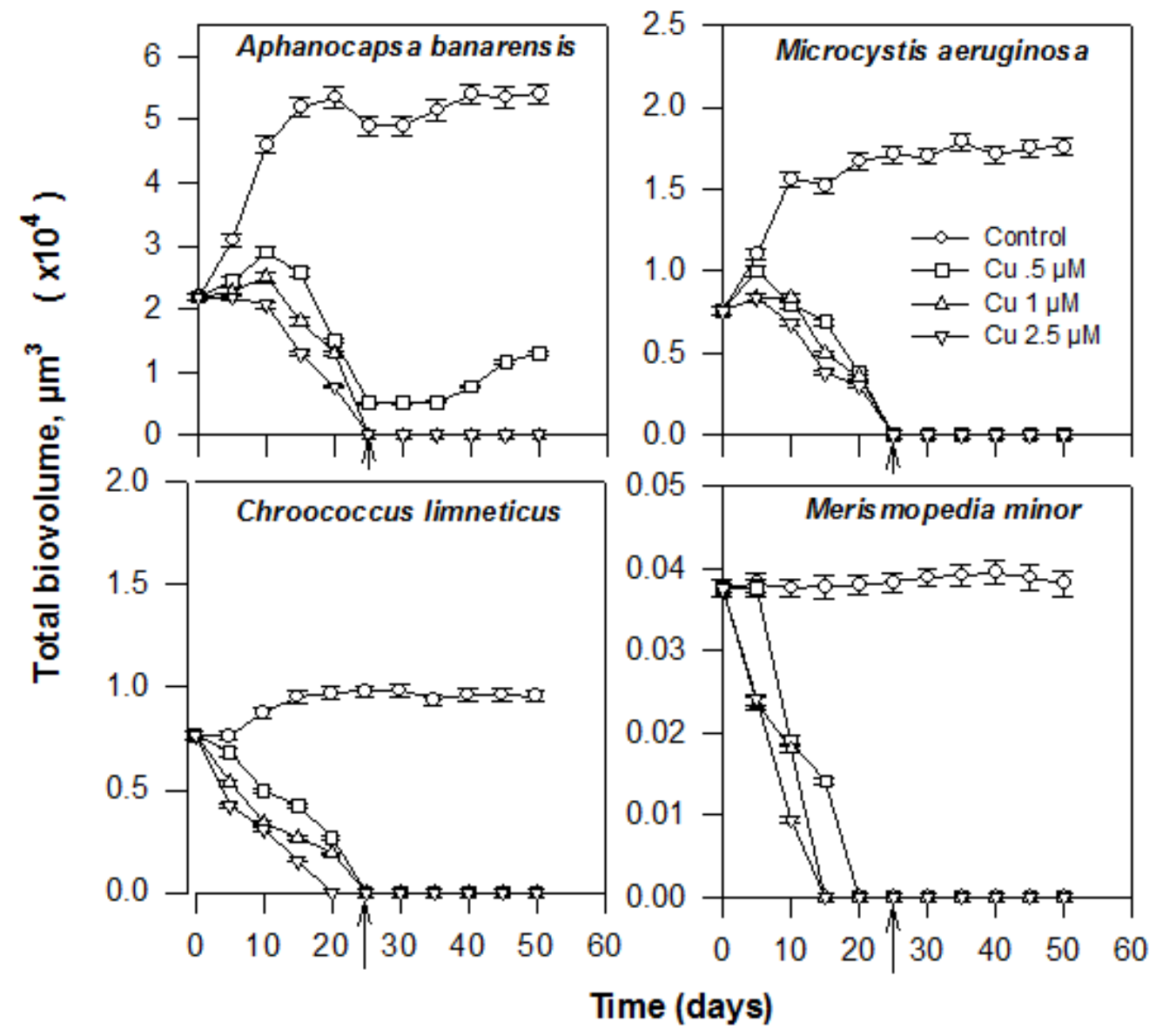

Figure 5

Total biovolume of major species belonging to Cyanophyta during exposure and recovery from Cu stress. Arrow indicates the time of transfer to the basal medium. Changes in the biovolume of different species of Cyanophyta were statistically significant with the passage of time $(P<0.001$, see table 2$)$, except for $C$. limneticus and M. minor in the control. 


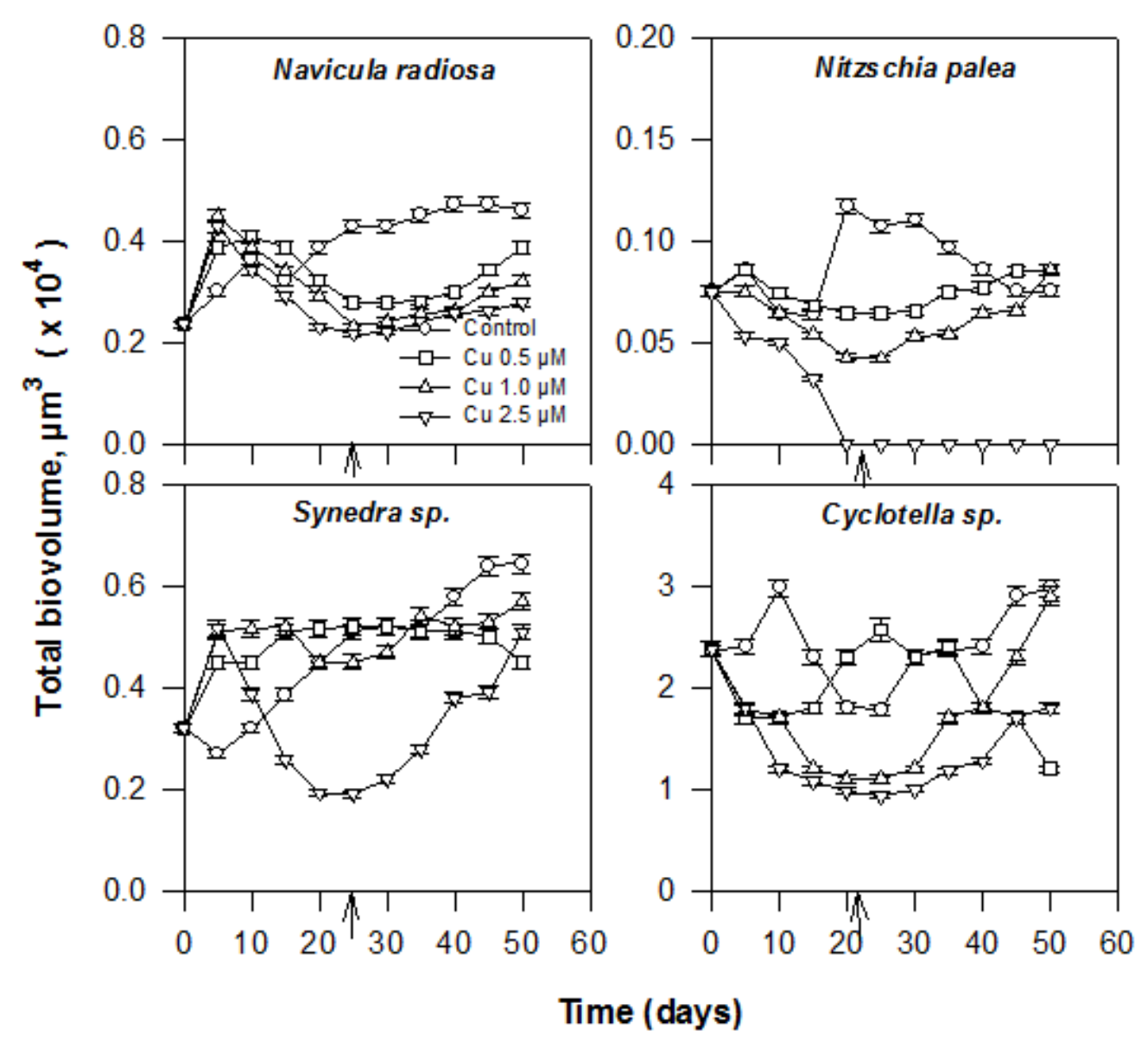

Figure 6

Total biovolume of major diatom species during exposure of an algal assemblage to $\mathrm{Cu}$, and also during recovery. Arrow indicates the time of transfer to the basal medium. Changes in the biovolume of differene diatom species were statistically significant $(P<0.001$, see table 2$)$ with the passage of time. 

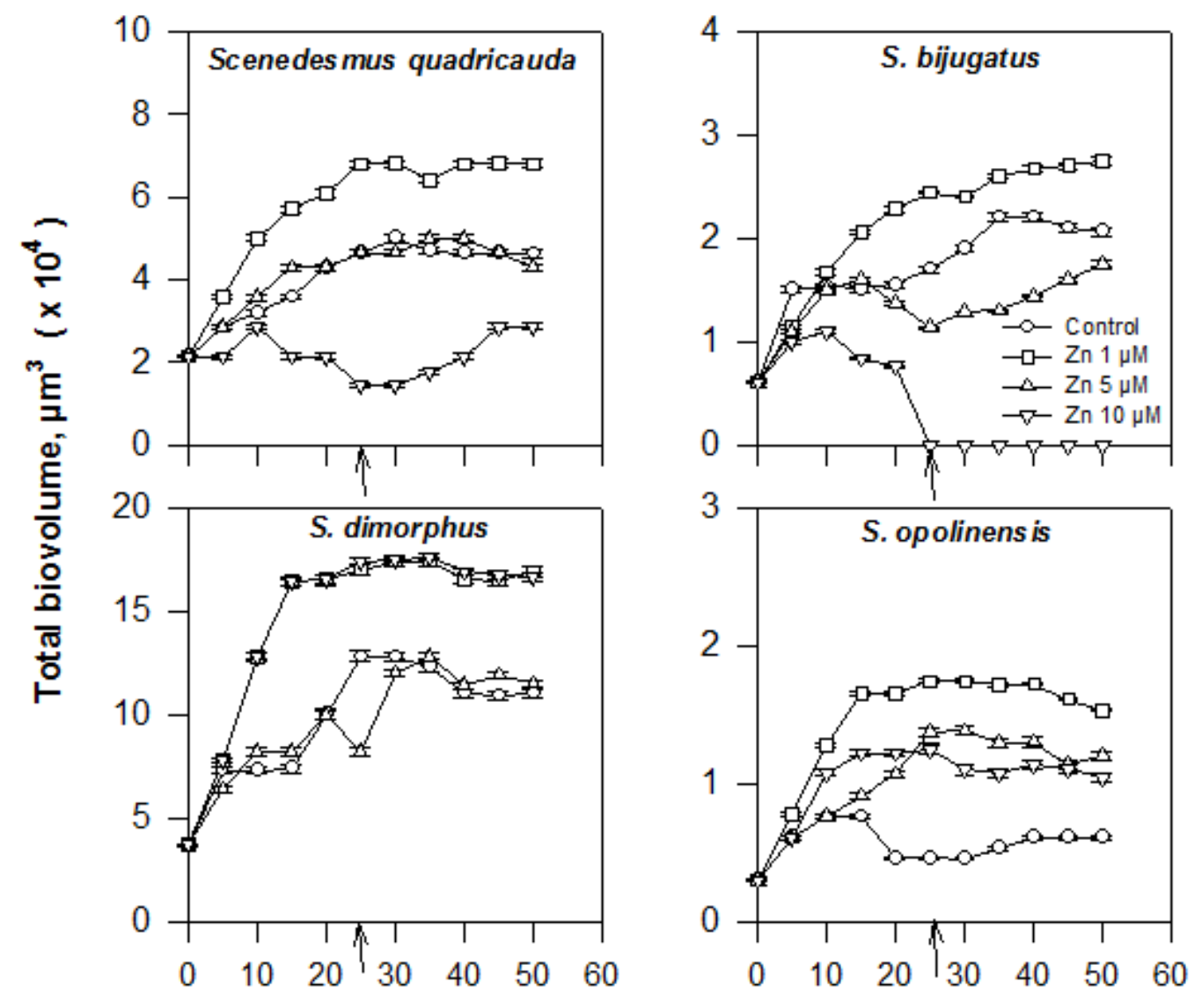

Figure 7

Total biovolume of four species of Scenedesmus (Chlorophyta) during exposure of the assemblage to Zn, and also during recovery. Arrow indicates the time of transfer to the basal medium. Changes in biovolume of species of Scenedesmus were statistically significant $(P<0.001$, see table 2$)$ with passage of time. 


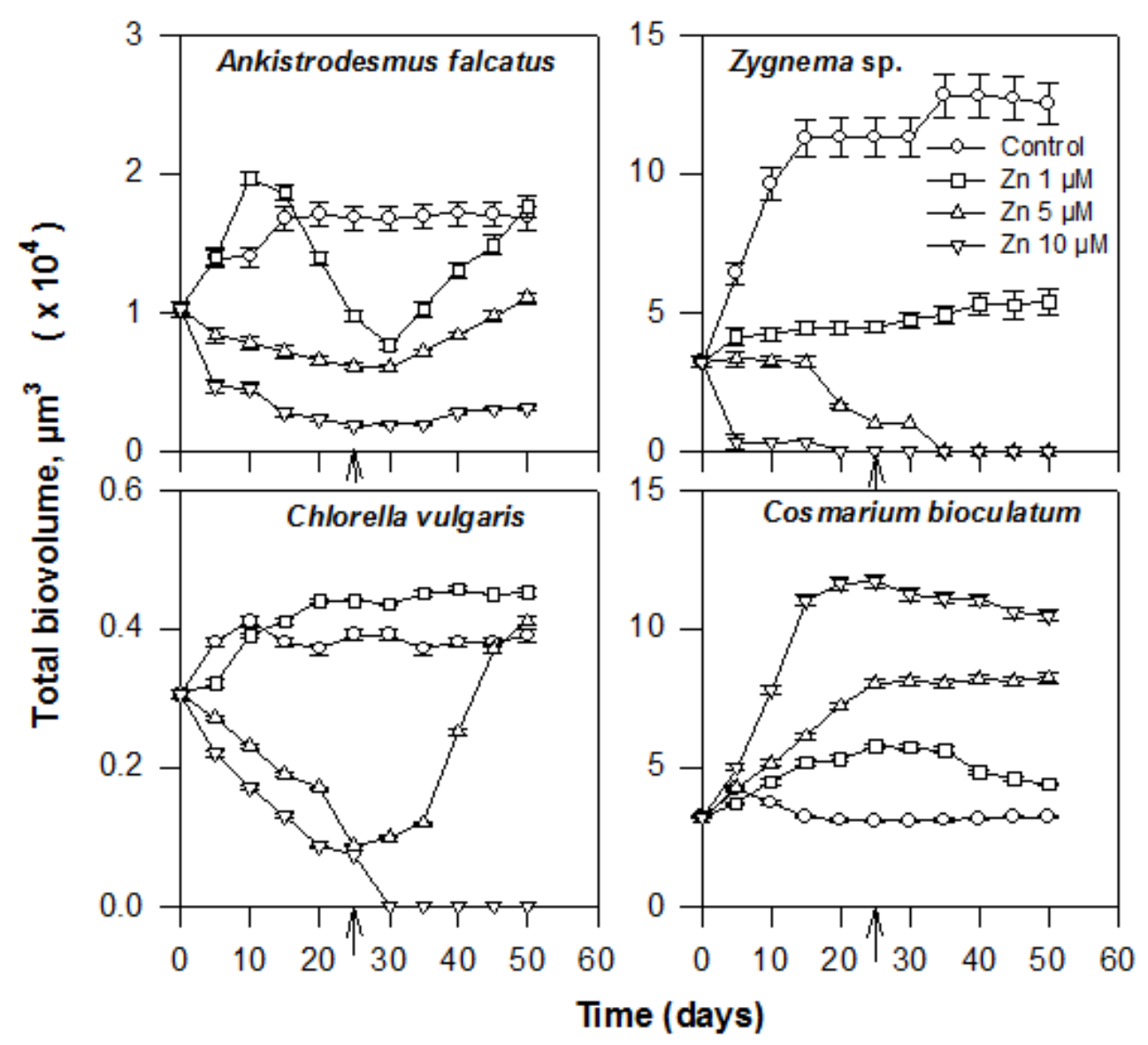

Figure 8

Total biovolume of some major green algal species during exposure of an algal assemblage to $\mathrm{Zn}$, and also during recovery. Arrow indicates the time of transfer to the basal medium. Changes in the biovolume of different green algal species were statistically significant $(P<0.001$, see table 2$)$ with the passage of time. 


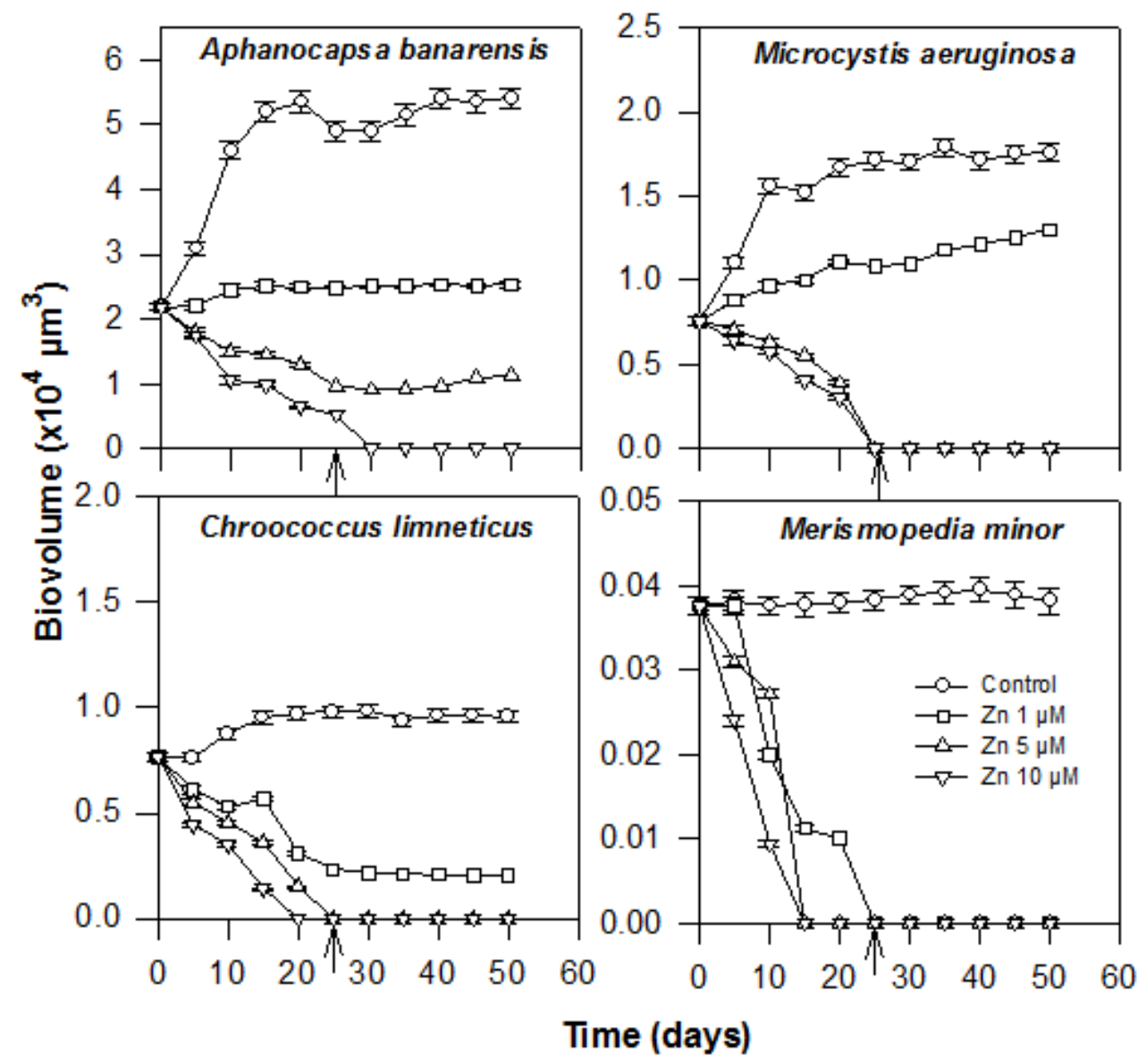

Figure 9

Total biovolume of major species belonging to Cyanophyta during exposure to $\mathrm{Zn}$ and also during recovery. Arrow indicates the time of transfer to the basal medium. Changes in the biovolume of different species of cyanophyta were statistically significant with the passage of time $(P<0.001$, see table 2$)$, except in $C$. limneticus and M. minor in the control culture and $\mathrm{A}$ banarensis at $1 \mu \mathrm{M} \mathrm{Zn}$. 


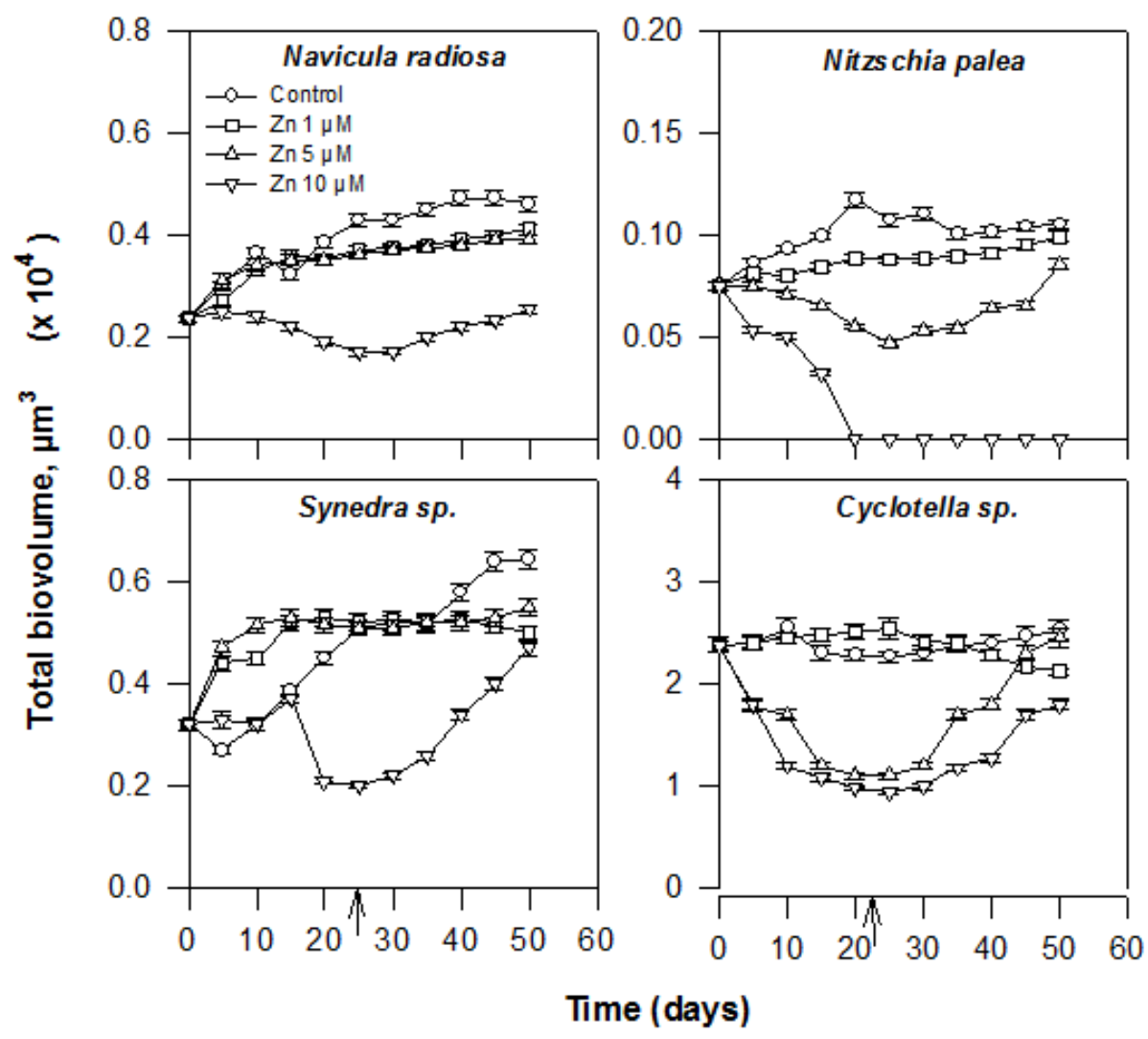

Figure 10

Total biovolume of major diatom species during exposure of an algal assemblage to $\mathrm{Zn}$, and also during recovery. Arrow indicates the time of transfer to the basal medium. Changes in the biovolume of diatom species were statistically significant $(P<0.001$, see table 2$)$ with the passage of time. 